\title{
Vinte anos da lei do SNUC: Histórico e momento atual das unidades de conservação em Mato Grosso do Sul
}

\section{Twenty years of the SNUC Law: History and current moment of conservation units in Mato Grosso do Sul}

\author{
Rafael Martins Brito \\ Doutorando em Geografia pelo programa de Pós-Graduação em Geografia \\ da Universidade Federal de Mato Grosso do Sul, Brasil \\ rafaelgeografiaufms@gmail.com \\ Patricia Helena Mirandola García \\ Doutora em Geografia pela Universidade Federal do Rio de Janeiro (UFRJ) \\ Professora da Universidade Federal de Mato Grosso do Sul, Brasil \\ patriciaufmsgeografia@gmail.com \\ Eduardo Salinas Chávez \\ Doutor em Geografia pela Universidad de la Habana \\ Professor visitante da Universidade Federal de Mato Grosso do Sul, Brasil \\ esalinasc@yahoo.com
}

\begin{abstract}
Resumo
No Brasil, a Lei $\mathrm{n}^{0} 9.985$ que institui o Sistema Nacional de Unidades de Conservação da Natureza completa vinte anos em 2020. Nesse cenário, o objetivo deste trabalho foi verificar a expansão das Unidades de Conservação no estado de Mato Grosso do Sul ao longo das últimas décadas e a representatividade de suas categorias no Sistema Estadual de Unidades de Conservação. Os resultados mostram que $15,20 \%$ da área do estado é provida de unidades de conservação, sendo $13,90 \%$ de uso sustentável, $0,38 \%$ de uso sustentável indireto (RPPNs) e $0,92 \%$ de proteção integral. O Sistema Estadual mostra um crescimento expressivo principalmente após a criação da Lei do SNUC, privilegiando principalmente as categorias de uso direto, como as APAs, em número de unidades e extensão. A desconexão entre os dados e a busca pelo equilíbrio por diferentes categorias de manejo estão entre os principais desafios identificados.
\end{abstract}

Palavras-chave: Unidades de Conservação; Áreas Protegidas; Lei do SNUC; Mato Grosso do Sul.

\begin{abstract}
In Brazil, Law No. 9.985 that institutes the National System of Conservation Units completes twenty years in 2020. In this scenario, this study aimed to verify the expansion of Conservation Units in the state of Mato Grosso do Sul over the last decades and the representativeness of their categories in the State System of Conservation Units. The results show that $15,20 \%$ of the state's area is provided with conservation units, with $13,90 \%$ of sustainable use, $0,38 \%$ of indirect sustainable use (RPPNs), and $0,92 \%$ of full protection. The state system shows an expressive growth principally after the creation of the SNUC Law, favouring mainly, the categories of direct use such as APAs, in the number of units and extension. The disconnection between the data and the search for balance by different management categories are among the main challenges identified.
\end{abstract}

Keywords: Units of Conservation; Protected Areas; SNUC Law; Mato Grosso do Sul. 


\section{INTRODUÇÃO}

O progresso feito ao longo do tempo pela humanidade, assim como a prosperidade das economias atuais, depende diretamente da exploração da diversidade biológica existente no planeta, de onde deriva uma gama de bens e serviços que contribuem para o bem-estar da humanidade (ARAÚJO, 2007).

Estima-se que o Brasil, país considerado megadiverso, como exposto em Rodrigues (2005), abriga cerca de $20 \%$ de toda biodiversidade encontrada no planeta e que $45 \%$ de todo produto interno bruto seja derivado do uso de recursos da biodiversidade (BRASIL, 2017). O estado de Mato Grosso do Sul, localizado no Centro-Oeste do Brasil, com 357.145,535 Km², está em uma região considerada estratégica no que se refere à biodiversidade do país, abrigando em seu território os biomas Cerrado, Pantanal e Mata Atlântica.

Os biomas Cerrado, segundo maior bioma brasileiro em extensão, considerado um dos hotspots da biodiversidade no mundo; Pantanal, maior planície alagável do planeta e Reserva da Biosfera com enorme riqueza de espécies; e Mata Atlântica, segunda maior floresta pluvial tropical do continente americano, que abrigam diversas espécies ameaçadas de extinção, sofreram e ainda sofrem, com a abertura de novas fronteiras para exploração de recursos naturais. Essas transformações têm sido um obstáculo e ao mesmo tempo um árduo desafio enfrentado em relação à preservação da biodiversidade, envolvendo diferentes atores e seus interesses por vezes conflitantes (KLINK; MACHADO, 2005; TABARELLI et al., 2005; ZEE, 2009; GRACIOLLI et al., 2017).

As Áreas Protegidas, mais especificamente as Unidades de Conservação (UCs), além de essenciais para a biodiversidade, estão entre as principais estratégias em nível mundial para fins de conservação (DUDLEY, 2008; BARRETO; DRUMMOND, 2017). Como parte das estratégias e planos de ação para o Brasil, a Convenção sobre a Diversidade Biológica (CDB), por meio do Plano Estratégico de Aichi em 2010, na 10ª Conferência das Partes (COP-10), estipula que até o ano de 2020 pelo menos 30\% da Amazônia e 17\% de cada um dos outros biomas deveriam ser conservados por áreas protegidas, dentre elas as unidades de conservação.

O Sistema Nacional de Unidades de Conservação (SNUC), instituído a partir da Lei $\mathrm{n}^{\circ}$ 9.985/2000, foi responsável pela sistematização e padronização das diferentes categorias de manejo pré-existentes e estabelece critérios e normas para a implantação e gestão das unidades de conservação no Brasil.

Apesar de ser o primeiro estado a implantar a Reserva Particular do Patrimônio Natural (RPPN), a história de criação dessas áreas no estado de Mato Grosso do Sul pode ser considerada recente, como um dos últimos membros da União a destinar parte de seu território a unidades de conservação. Alguns estudos importantes vêm sendo desenvolvidos em relação às UCs no estado, 
como o de espécies ameaçadas, de administração e situação ambiental das unidades, de motivações e incentivos para a criação de RPPNs, de gestão do ICMS-Ecológico, entre outros (TORRECILHA et al., 2017; SANTOS; KRAWIEC, 2011; PELLIN; RANIERI, 2009; MOREIRA, 2004).

Contudo, identifica-se uma lacuna a ser explorada quanto à evolução da distribuição espacial, extensão territorial e as características das unidades de conservação criadas no estado, principalmente no que se refere às suas categorias de manejo. Portanto, este trabalho justifica-se mediante a necessidade de entendimento da situação atual das UCs no estado, após 20 anos da criação da Lei do SNUC, e do comportamento de distribuição de suas categorias ao longo dos anos nas diferentes esferas do governo. Sendo assim, o objetivo deste estudo é de verificar a expansão das UCs no estado de Mato Grosso do Sul ao longo das últimas décadas, a sua representatividade por biomas e, por conseguinte, as suas características no Sistema Estadual de Unidades de Conservação.

\section{BREVE HISTÓRICO DOS MOVIMENTOS DE CRIAÇÃO DE ÁREAS PROTEGIDAS NO MUNDO, NO BRASIL E A LEI DO SNUC}

Após séculos de devastação e do uso indiscriminado dos recursos naturais, impulsionados pelo avanço das técnicas e pelo aumento de sua população, a pressão exercida pelo homem sobre a natureza e os reflexos do comprometimento do equilíbrio do ambiente já eram sentidos desde meados do século XIX.

A noção da intensa modificação dos habitats causada pela rápida industrialização e consequente crescimento das cidades e a proliferação de ambientes insalubres e "feios" despertaram em parte da sociedade a consciência da necessidade da criação de espaços naturais destinados à preservação da natureza (fauna e flora) e também para a contemplação, reflexão, isolamento espiritual, funcionando propriamente como refúgios do caos urbano (DORST, 1973; ARAÚJO, 2007). Portanto, o conceito de Áreas Protegidas vem sendo empregado desde a segunda metade do século XIX nos Estados Unidos, onde a principal finalidade era proteger a vida selvagem do comportamento nocivo, causado pela civilização urbano-industrial, culminando em ameaças à natureza (DIEGUES, 2008).

Muito embora as medidas direcionadas à proteção da natureza e a espécies peculiares da fauna sejam datadas desde a antiguidade ${ }^{1}$ e a Reserva Florestal mais antiga ser a Reserva de Tobago, nas Ilhas de Trindade e Tabago, considera-se como evento fundamental na estratégia de criação e popularização de Áreas Protegidas, ${ }^{2}$ a criação do Parque Nacional de Yellowstone nos EUA em 1872 ,

\footnotetext{
${ }^{1}$ Segundo Dorst (1973), há exemplos desde a Europa Ocidental até a Ásia de áreas protegidas na antiguidade, como os decretos do imperador hindu Asoka, datados de 242 a.C. concedendo proteção a peixes, animais terrestres e florestas, assim como o duque Boleslaus da Mazóvia, já no fim do século XIII, que proibia a caça do Auroque em seus domínios.

2 Segundo Pureza (2014), o uso do termo "unidades de conservação" é restrito ao Brasil, sendo mais comum internacionalmente a utilização de "Áreas Protegidas".
} 
localizado entre os estados de Wyoming, Montana e Idaho. Os objetivos iniciais do surgimento dessas primeiras áreas, conforme explica Drummond et al. (2011), estavam diretamente relacionados à preservação de áreas terrestres ou aquáticas, possuidoras de características naturais raras ou grande beleza cênica, assim como a atenção especial para o que os autores chamam de exemplares "carismáticos" da fauna e da flora.

O exemplo da criação do Parque de Yellowstone inspirou a criação de diversas áreas protegidas pelo mundo. Além de ser um dos símbolos norte-americanos mais importantes de lazer, é marcado como referência no conceito de unidades de conservação modernas, alicerçando a fundamentação dos conceitos de manejo de parques nacionais (ARAÚJO, 2007; PUREZA, 2014).

Tratando-se do Brasil, a primeira proposta feita para a criação de Parques Nacionais partiu do engenheiro e abolicionista André Rebouças em 1876, sugerindo a criação do Parque Nacional das Sete Quedas e da Ilha do Bananal. ${ }^{3}$ De fato, o primeiro parque criado no Brasil foi concebido em âmbito estadual, o Horto Botânico na cidade de São Paulo em 1896, posteriormente denominado Parque Estadual São Paulo, embora, segundo Pureza (2014), o Parque do Itatiaia (1937) seja reconhecidamente considerado o marco principal, por ser a primeira unidade de conservação federal e a mais conhecida. Nos anos que se seguiram foram criados mais dois Parques Nacionais, o da Serra dos Órgãos e o do Iguaçu em 1939.

No Brasil, o Código Florestal de 1934 (Decreto no 23.793) se estabelece historicamente como um marco legislativo importante no âmbito das unidades de conservação. Em seu artigo $3^{\circ}$, o Código Florestal de 1934 classificava as florestas em quatro tipos: protetoras ${ }^{4}$ e remanescentes, sob regime de preservação permanente; modelo e produtivas, passíveis de exploração comercial. Em seu artigo $5^{\circ}$, o Código de 1934 declara as florestas remanescentes aquelas que formassem os parques nacionais, estaduais e municipais (ARAÚJO, 2007; DRUMMOND, 2011). Outras leis de suma importância foram instituídas na década de 1930, como o Código das Águas (1934), o Código de Mineração (1934) e o Código de Caça e Pesca (1934).

Segundo Pureza (2014), até a posterior Lei no 4.771 do Código Florestal de 1965, foram criados 16 Parques Nacionais no Brasil. Contudo, verificava-se a ausência de um ato legal que definisse os objetivos de manejo da categoria. A principal diferença observada entre o que foi estabelecido na Lei de 1934 e 1965, segundo Drummond (2011), fica por conta da inserção de unidades de conservação de uso indireto (Parques Nacionais, Estaduais e Municipais e Reservas Biológicas) e uso direto (Florestas Nacionais e Parques de Caça). Percebe-se, até então, que a criação de unidades de conservação no período pré-SNUC está desmembrada em diferentes setores do

\footnotetext{
${ }^{3}$ Anos depois foram criados nesses locais, o Parque Nacional do Araguaia (1959) e o Parque Nacional de Sete Quedas (1961) que deu lugar ao lago da barragem da Usina de Itaipu.

${ }^{4}$ Viria a se tornar o que são hoje as Áreas de Preservação Permanentes (APPs).
} 
governo e pouco articulada entre si, tendo em vista os diferentes decretos e órgãos responsáveis pela criação dessas Áreas Protegidas e sua categorização.

Conforme ressalta Mercadante (2001), até a década de 60, a criação de unidades de conservação não obedecia a nenhum planejamento mais abrangente, sendo estabelecidas principalmente por razões estéticas ou devido a circunstâncias políticas favoráveis. A responsabilidade pela administração das unidades de conservação no Brasil era do Ministério da Agricultura até 1967, onde passou a ser gerido pelo Instituto Brasileiro de Desenvolvimento Florestal $(\mathrm{IBDF}) .^{5}$

Anteriormente, conforme explana Pureza (2014), outros órgãos criados mediante preocupação com a gestão florestal no país abarcavam objetivos que combinavam conservação e restituição de florestas e o seu aproveitamento, como o Serviço Florestal Brasileiro (SFB), criado em 1921, e depois o Departamento de Recursos Naturais Renováveis (DRNR) em 1959.

Segundo Araújo (2007), mediante a influência causada pós conferência de Estocolmo, realizada em 1972 e suas recomendações aos países participantes, e a política que se seguia à época de desenvolvimento a qualquer custo, ${ }^{6}$ aliada às condições ambientais vividas no país, criou-se em 1973 a Secretaria Especial do Meio Ambiente (SEMA). A SEMA, à época ligada diretamente ao presidente da República, ${ }^{7}$ foi responsável, de acordo com Pureza (2014), pela criação de algumas categorias de unidades de conservação, como a Estação Ecológica (ESEC) - Lei no 6.513, a Área de Proteção Ambiental (APA) - Lei n 6.902, a Área de Relevante Interesse Ecológico (ARIE) e as Reservas Ecológicas - Decreto $\mathrm{n}^{\mathrm{o}} 89.336^{8}$.

No ano de 1989, SEMA e IBDF juntamente com as superintendências da Pesca e da Borracha foram unidos, dando origem ao Instituto Brasileiro do Meio Ambiente e dos Recursos Naturais Renováveis (IBAMA), que, segundo Rylands e Brandon (2005), fez parte de uma grande reestruturação e organização governamental das instituições ambientais no Brasil.

Nesse interim, entre as décadas de 1970 e 1980, elaboraram-se os primeiros planejamentos do que viria a ser o Sistema de Unidades de Conservação brasileiro, com a finalidade de consolidar, padronizar e criar novas categorias e alinhar seus objetivos. Por meio do IBDF e em parceria com a organização não governamental Fundação Brasileira para Conservação da Natureza (FBCN), efetuou-se a elaboração do chamado "Plano do Sistema de Unidades de Conservação do Brasil”, aprovado e publicado em 1979 (PÁDUA, 2011).

\footnotetext{
${ }^{5}$ Segundo Araújo (2007), ao IBDF foram incorporados o Departamento de Recursos Naturais Renováveis (DRNR), o Conselho Florestal Federal, o Instituto Nacional do Pinho e o Instituto Nacional do Mate.

${ }^{6}$ Em Araújo (2007, p. 73) é trazida uma contextualização das unidades de conservação no período do regime militar (1964-1985) e suas políticas desenvolvimentistas.

${ }^{7}$ Informação fornecida por José Augusto Drummond em Brasília, 2013 disponível em Pureza (2014, p. 33).

${ }^{8}$ Há também relatos em Pureza (2014, p. 34) de Paulo Nogueira Neto de como a SEMA iniciou seus trabalhos voltados para diminuição da poluição e passou a criar Unidades de Conservação.
} 
A segunda etapa desse projeto foi publicada em 1982. Contudo, segundo Medeiros (2006), por razões políticas, essas propostas acabaram sendo inviabilizadas. Apenas em 1989 gerou-se, pela parceria entre IBDF, SEMA e FUNATURA (esta última guiada por Maria Tereza Jorge Pádua), o "Sistema Nacional de Unidades de Conservação (SNUC) - Aspectos Conceituais e Legais". Este trabalho, segundo Pádua (2011, p. 23), foi solicitado com a intenção de “[...] revisão e atualização conceitual do conjunto de categorias de unidades de conservação, incluindo a elaboração de um Anteprojeto de Lei, para dar suporte legal ao sistema".

Com base nesse trabalho em conjunto com dois anteprojetos de $\mathrm{lei}^{9}$ apresentados, respaldando a base legal para que as formulações fossem implementadas, transcorreu-se no legislativo e no executivo longas discussões durante uma década. Segundo Medeiros (2006, p.57), “[...] entre os pontos mais polêmicos destacavam-se a questão das populações tradicionais, a participação popular no processo de criação e gestão de UCs e as indenizações para desapropriações".

Assim, após um longo embate, entre ambientalistas, preservacionistas, socioambientalistas e ruralistas, a aprovação da Lei do Sistema Nacional de Unidades de Conservação (SNUC) aconteceu no dia 18 de julho de 2000. A Lei n ${ }^{\circ}$ 9.985/2000 do SNUC estabelece critérios e normas para a criação, implementação e gestão de UCs em âmbito federal, estadual e municipal, e as entende como

[...] espaço territorial e seus recursos ambientais, incluindo as águas jurisdicionais, com características naturais relevantes, legalmente instituído pelo Poder Público, com objetivos de conservação e limites definidos, sob regime especial de administração, ao qual se aplicam garantias adequadas de proteção (MMA, 2004, p. 7).

Pela Lei, as UCs estão divididas em dois grupos: Unidades de Proteção Integral (PI) e Unidades de Uso Sustentável (US). As categorias de manejo PI são a Estação Ecológica (ESEC), a Reserva Biológica (REBIO), o Parque (Nacional, Estadual e Municipal), o Monumento Natural (MONA) e o Refúgio da Vida Silvestre (RVS). Dentre as categorias de US, estão a Área de Proteção Ambiental (APA), a Área de Relevante Interesse Ecológico (ARIE), a Floresta Nacional (FLONA), a Reserva Extrativista (RESEX), a Reserva de Fauna (REFAU) e a Reserva de Desenvolvimento Sustentável (RDS).

\section{PROCEDIMENTOS METODOLÓGICOS}

Os procedimentos utilizados para a realização deste trabalho se sustentam pelas consultas ao banco de dados do Cadastro Nacional de Unidades de Conservação (CNUC), ${ }^{10}$ assim como do Cadastro Estadual de Unidades de Conservação do Estado de Mato Grosso do Sul (CEUC), ${ }^{11}$ indicado

\footnotetext{
${ }^{9}$ Em 1992 tomou forma como o Projeto de Lei n ${ }^{\circ}$ 2.892/92, segundo Medeiros (2006).

${ }^{10}$ www.mma.gov.br/areas-protegidas/cadastro-nacional-de-ucs.

${ }^{11}$ www.imasul.ms.gov.br/cadastro-estadual-de-unidades-de-conservacao-ceuc/.
} 
na Lei $\mathrm{n}^{\mathrm{o}}$ 4.219/2012. Os arquivos em formato shapefile, utilizados para indicar a representação espacial dessas unidades e sua extensão em ambiente de Sistema de Informação Geográfica - SIG (ArcGis 10.3.1), foram adquiridos no Sistema Interativo de Suporte ao Licenciamento Ambiental (SISLA). Trata-se, pois, de sistema voltado para o licenciamento e fiscalização ambiental, um dos produtos do projeto GEOMS, desenvolvido pela Empresa Brasileira de Pesquisa Agropecuária (EMBRAPA) e pelo Instituto de Meio Ambiente de Mato Grosso do Sul (IMASUL).

Dentre algumas informações utilizadas estão: nome da UC, categoria, esfera de criação, ano de criação, bioma, arquivo em shapefile dos limites da unidade, cadastro no CNUC, cadastro no CEUC e a existência ou não do plano de manejo. É válido observar que, em alguns casos, as UCs cadastradas no órgão estadual não apresentam suas informações no cadastro nacional, bem como algumas delimitações de UCs que constam no projeto GEOMS não aparecem no cadastro Estadual ou Nacional.

Em razão da desarticulação apresentada entre os dados das plataformas consultadas, optouse por selecionar as UCs presentes no CEUC ou as que apresentam sua delimitação no SISLA, por possibilitar uma análise mais abrangente. A razão para a escolha desses critérios explica-se pelo fato de que, se trabalhadas apenas as UCs devidamente cadastradas no CNUC, as informações sobre as áreas protegidas no Estado seriam insuficientes e não condizentes com a realidade apresentada atualmente. $^{12}$

A utilização do CNUC foi aplicada para fins de comparação dos dados obtidos no estado de Mato Grosso do Sul com outros estados da Federação, possibilitando uma visão mais abrangente da situação das UCs no estado. Optou-se por analisar as informações em três períodos distintos e relevantes da criação de UCs no estado, sendo: (i) o período anterior à Lei do SNUC (até o ano 2000); (ii) pós Lei do SNUC, analisando incentivos do estado para a criação de UCs, como o ICMS Ecológico (até o ano 2010); e (iii) os últimos nove anos (até o ano 2019).

\section{RESULTADOS E DISCUSSÕES}

O movimento de implantação de UCs no estado de Mato Grosso do Sul pode ser considerado recente em comparação a outros estados como São Paulo, Rio de Janeiro, Minas Gerais, sendo uma das últimas unidades da Federação a abrigar UCs tanto em nível federal como estadual.

Mesmo com a criação de 13 RPPNs $^{13}$ na década de 1990, anteriormente algumas unidades haviam sido criadas em âmbito federal, envolvendo o território Sul-matogrossense, em conjunto com outros estados, como é o caso do Parque Nacional das Emas, com Goiás, no ano de 1961 (Decreto nº.

\footnotetext{
${ }^{12} \mathrm{O}$ responsável pelo cadastro no CNUC é o próprio órgão gestor da UC.

${ }^{13}$ A RPPN Fazenda Lageado foi a primeira a ser criada no estado e no Brasil em 1990 na cidade de Dois Irmãos do Buriti.
} 
49.874); e o Parque Nacional do Pantanal Matogrossense, com Mato Grosso, em 1981 (Decreto-Lei $\mathrm{n}^{\circ} 86.392$ ), ocupando por sua vez pequenas extensões do estado, respectivamente 3.273 ha e 660,807 ha de sua zona de amortecimento.

Anterior ao surgimento das RPPNs nos anos 90, que serviu como ferramenta para a consolidação da conservação da biodiversidade em Mato Grosso do Sul, havia sob domínio do estado apenas uma unidade de conservação, à época denominada Reserva Ecológica Parque dos Poderes, na capital Campo Grande, criada em 1981 pelo Decreto Estadual n ${ }^{\circ}$ 7.122/81, que mediante readequação às exigências da Lei do SNUC tornou-se pelo Decreto Estadual no 10.783, de 21 de maio de 2002, o Parque Estadual do Prosa (IMASUL, 2019).

Nota-se, a partir de 1998, um avanço e uma mobilização no tocante à criação de UCs no âmbito estadual, nos quais estão inseridos o Parque Estadual das Várzeas do Rio Ivinhema, em 1998 (Decreto $n^{\circ}$ 9.278/1998); o Parque Estadual Nascentes do Rio Taquari, em 1999 (Decreto $n^{\circ}$ 9.662/1999); Parque Estadual Matas do Segredo, em 2000 (Decreto n 9.935/2000); o Parque Estadual Pantanal do Rio Negro, em 2000 (Decreto n 9.941/2000); e, também, o Parque Nacional Serra da Bodoquena (Decreto Fed. s/nº 21/09/2000), primeiro Parque Nacional (PARNA) situado inteiramente no estado.

No decorrer desse período, também nota-se uma variação maior no contexto de criação das unidades a respeito de suas categorias de manejo, dentre elas as de uso sustentável, como as Áreas de Proteção Ambiental (APA), e de Proteção Integral, como os Monumentos Naturais (MONA), e mais recentemente, as categorias Estação Ecológica, Reserva Biológica e Refúgio da Vida Silvestre.

\subsection{Categorias, espacialização e situação das UCs no estado de Mato Grosso do Sul}

Atualmente no estado de Mato Grosso do Sul, as categorias de manejo que integram o Sistema Estadual de Unidades de Conservação (SEUC) são as Áreas de Proteção Ambiental (APA), o Parque Nacional, Estadual e Municipal (PARNA, PE e PNM), o Monumento Natural (MONA), a Estação Ecológica (ESEC), a Reserva Biológica (REBIO), o Refúgio da Vida Silvestre (RVS) e a Reserva Particular do Patrimônio Natural (RPPN). Cabe ressaltar que, no caso das RPPNs, embora figurem dentro do grupo de Uso Sustentável, essas unidades na Lei do SNUC são de uso indireto, designando em seus objetivos o uso dessas áreas para fins turísticos, recreativos e educacionais, vetando o uso de seus recursos para outros fins ${ }^{14}$.

\footnotetext{
${ }^{14}$ Tal situação, segundo Pádua (2011), explica-se pelos interesses envolvidos à época da discussão para a aprovação da Lei do SNUC, onde por parte dos proprietários de terra e grileiros havia o interesse no uso dos recursos dessa categoria, além da isenção do imposto territorial, e por parte dos ambientalistas o de preservação de seus recursos, resultando desse embate o veto presidencial de parte do Artigo 21, tornando a categoria de fato uma UC de proteção integral, mesmo alocada no grupo de Uso Sustentável, onde segundo a autora, "o Presidente não podia vetar os artigos da categorização, espinha dorsal da Lei do SNUC, por isso o remendo mal explicado".
} 
Até 2000, ano que marcou a aprovação da Lei do SNUC, o estado apresentava: quatro PARNAs, quatro Parques Estaduais (PEs), dois Parques Naturais Municipais (PNMs), quatro APAs e 13 RPPNs, sendo as UCs do grupo de Uso Sustentável responsáveis pela cobertura de 2,17\% da área total do estado, 13 RPPNs responsáveis por 0,20\% e o grupo de Proteção Integral com menos de $1 \%$ (Tabela 1$)$.

Tabela 1 - Distribuição da área de cobertura das UCs por grupo de manejo até o ano 2000.

\begin{tabular}{cccc}
\hline Grupo de Manejo & Número de UCs & Área em Hectares (ha) & Área no Estado (\%) \\
\hline Proteção Integral & 11 & $278.181,567$ & 0,77 \\
Uso Sustentável & 4 & $776.297,477$ & 2,17 \\
RPPNs* & 13 & $73.557,719$ & 0,20 \\
Total & $\mathbf{2 8}$ & $\mathbf{1 . 1 2 8 . 0 3 6 , 7 6 3}$ & $\mathbf{3 , 1 4}$ \\
\hline \multicolumn{4}{c}{ * O cálculo não conta com o polígono da RPPN Lageado. } \\
Fonte: Elaborada com base nos dados de UNICECO/GUC/IMASUL (2018).
\end{tabular}

Apresenta-se clara a importância da categoria Parque, sendo a principal forma de criação de UCs de Proteção Integral no estado, em número de unidades e em extensão, tendência que se mantém até os dias atuais. Após esse período, nenhum outro PARNA ou PE foi criado no estado, mantendose a mesma extensão de proteção verificada até o ano 2000. O avanço dessa categoria em números de UCs e extensão se deu na esfera municipal, onde entre 2001 e 2010 foram criados 11 PNMs, com uma área de 25.844,247 ha.

Praticamente no mesmo período, observou-se também um avanço de criação de UCs das demais categorias, tanto de US como de PI, tendência observada também por Drummond (2011), em âmbito nacional na primeira década dos anos 2000, onde foram criadas 115 UCs na esfera Federal, somando mais de 37 milhões de hectares. No caso do estado de Mato Grosso do Sul, entre os anos de 2001 e 2010, foram criadas 73 UCs, como mostra os dados da Figura 1.

Número de UCs criadas entre 2001 e 2010

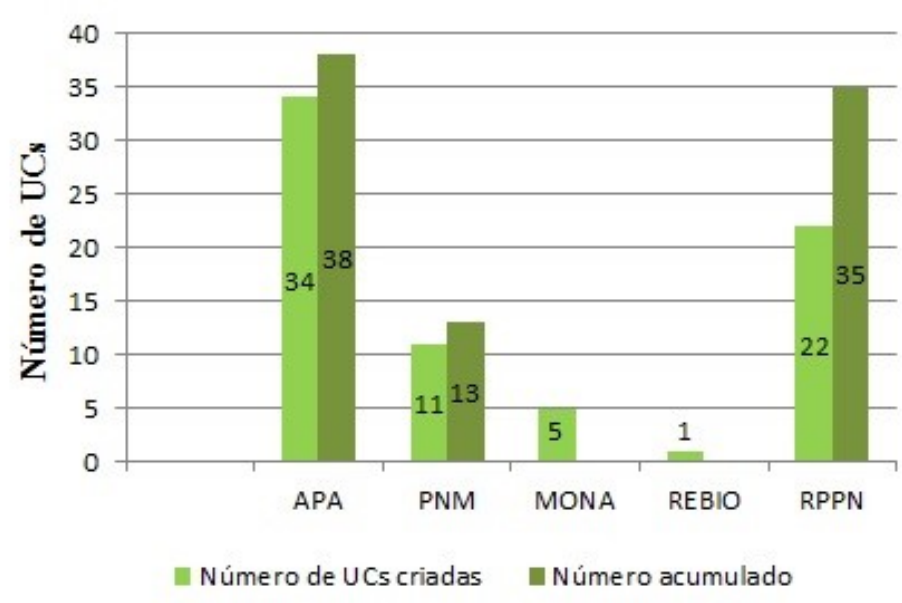

Figura 1 - UCs Criadas em MS entre os anos de 2001 e 2010. Fonte: Elaborado com base nos dados de CEUC (2018). 
No período entre 2001 e 2010, é interessante observar o aumento expressivo de $750 \%$ no número de UCs de US da categoria APA, alcançando uma área de aproximadamente 2.857.691,900 hectares. Um dos motivos dessa rápida expansão pode ser explicado pela implantação do programa Estadual do ICMS Ecológico. Em 1994, a Lei Complementar nº 077/94 modificou a parcela do critério igualitário do ICMS no Estado, disposto na Lei Complementar n ${ }^{\circ}$ 057/91, reduzindo o percentual de $12 \%$ para $7 \%$, aplicando o restante dos 5\% para os municípios que possuem UCs em seu território; e em 2001, a Lei Estadual nº 2.259 regulamenta a Lei 077/94 e estabelece gradualmente a porcentagem do ICMS Ecológico que era de 2\% em 2002 para 5\% de 2004 em diante (MOREIRA, 2004).

O aumento da criação das APAs, principalmente no âmbito da esfera municipal, evidencia algumas questões importantes como a efetividade de proteção e a diversidade biológica concebida por essas áreas. Se considerarmos os propósitos de criação destas unidades, certamente teremos em prospecção análises dos benefícios advindos de um maior controle do espaço delimitado como área de abrangência.

Entretanto, as grandes extensões dessas categorias de UCs e as dificuldades de ordenamento territorial e de custos operacionais podem limitar consideravelmente os pressupostos observados em lei. Pádua (2011) já expressava tal preocupação ao observar a criação de APAs em diversas regiões do país com enormes extensões e pouca efetividade em ações práticas, servindo basicamente como instrumento de ordenamento territorial, atentando-se ao fato de que a "[...] proteção não está assegurada somente pelos decretos de criação" (PÁDUA, 2011, p.26).

A análise da efetividade de gestão pode ser determinada por meio de critérios obtidos através de indicadores pré-selecionados em relação aos padrões da UC, onde o termo efetividade reflete basicamente três temas principais: a avaliação do desenho da área protegida e do sistema de áreas protegidas, adequação dos sistemas e processos de gestão e a entrega dos objetivos (resultados) e conservação de valores (HOCKINGS et al., 2006). Portanto, a efetividade das UCs pode variar caso a caso, mesmo fazendo parte de um mesmo grupo (Proteção Integral ou Uso Sustentável), a categoria e os objetivos de sua criação, localização, relação com o entorno, qualidade do zoneamento proposto, instrumentos de fiscalização, recursos materiais e humanos disponíveis, são alguns dos fatores que influenciam na efetividade de seu manejo.

Correntes preservacionistas e conservacionistas ${ }^{15}$, consolidadas ao final do século XIX e início do século XX, proporcionaram mediante os desdobramentos de seus preceitos e discussões, entre outros resultados, a pluralidade de categorias de manejo observadas nas diferentes UCs ao redor

\footnotetext{
${ }^{15}$ Araújo (2007) explica que, o conceito de preservação objetiva a criação de zonas intangíveis à ação do homem para a proteção de espécies da fauna e flora, além de áreas específicas, enquanto o conceito de conservação busca a exploração dos recursos naturais em harmonia com meio ambiente, sem prejuízo ao social e o ambiental.
} 
do mundo (ARAÚJO, 2007). Dourojeanni e Pádua (2013, p.133), em uma análise específica sobre as APAs no Brasil, discorrem de forma incisiva a respeito da situação desta categoria, sobre seus excessos territoriais e dificuldades operacionais, afirmando que “[...] com raríssimas exceções, parecem não serem úteis para nada, pois estar nelas ou fora delas não faz maior diferença".

No caso de MS, é possível citar, por exemplo, algumas APAs localizadas ao Leste do estado, onde sua extensão ocupa quase a totalidade da área de seus municípios, como a APA da Bacia do Rio Sucuriú e APA Serra das Morangas, em Inocência, com 458.276,473 ha (79,38\% do município), APA do Rio Sucuriú-Paraíso e APA do Rio Verde, em Paraíso das Águas, com 501.208,286 ha (99,55\% do município), APA das Bacias do Rio Aporé e do Rio Sucuriú, em Chapadão do Sul, com 298.702,918 ha (91,96\% do município), APA das nascentes do Rio Sucuriú, em Costa Rica, com 294.436,917 ha (70,67\% do município) e APA da sub-bacia do Rio Aporé, em Cassilândia, com $136.628,567$ ha $(37,45 \%$ do município).

Nesse sentido, o IMASUL (2011), ao discorrer sobre o assunto no Plano de Manejo do Parque Estadual do Prosa, já indicava em um cenário de curto a médio prazo os desafios e percalços para a consolidação dessas áreas e a necessidade de suporte técnico e institucional do Estado em favor dos municípios para a efetiva implementação dessas unidades. É necessário pontuar que, além de disciplinar o processo de ocupação e assegurar a sustentabilidade do uso dos recursos naturais, o artigo $15^{\circ}$ da Lei do SNUC também prevê e versa sobre a importância de proteger a diversidade biológica dessas áreas.

No período entre 2001 e 2010, também foram implantadas outras categorias de proteção integral, sendo cinco MONAs (duas estaduais e três municipais), que somadas alcançavam 15.969,732 há, e a única REBIO do estado até então, localizada em Três Lagoas, com 63,662 ha. Ainda segundo Pádua (2011), encontra-se nesse período, também em nível Federal, certa dificuldade em criar-se UCs de uso indireto, citando o intervalo de oito anos sem a criação de uma única REBIO, situação semelhante com a encontrada no estado nesse período, onde as UCs de uso sustentável sobressaíram em números e em extensão em relação às de proteção integral.

O crescimento da categoria MONA pode ser explicado pelo fato de que, mesmo sendo de proteção integral, pode-se estabelecer esse tipo de categoria em áreas particulares, desde que compatibilizados os objetivos da UC e da propriedade. Como exemplo da expansão dessa categoria no estado, pode-se citar o Monumento Natural Municipal Serra do Bom Jardim, em Alcinópolis, criado em 2003 e que encontra-se localizado em parte de 11 propriedades particulares, em uma área de aproximadamente 5.597,63 ha. 
As RPPNs no período assinalado pela Figura 1 apresentam o segundo maior avanço, visto que foram criadas $22 \mathrm{UCs}$, totalizando uma área de 45.583,760 ha. ${ }^{16}$ Mesmo individualmente, se tratando de unidades com extensões menores, quando comparadas às APAs, e pertencendo à categoria de Uso Sustentável, o fato de não permitirem o uso direto de seus recursos naturais as colocam em uma posição diferenciada no que diz respeito à proteção da biodiversidade.

As RPPNs no estado tiveram papel fundamental para o avanço do SEUC, como uma das primeiras ferramentas da política pública de conservação in situ da diversidade biológica do âmbito do Mato Grosso do Sul (IMASUL, 2011). A criação das RPPNs, pioneiras no estado, foi alavancada ainda mais a partir do Sistema Estadual de Reserva Legal (SISREL), pelo Decreto Estadual $n^{\circ}$ 12.528/2008, onde se estabelece incentivos e alternativas a partir da regularização fundiária das UCs de domínio público, possibilitando a constituição de Reserva Legal no interior das RPPNs (IMASUL, 2011). Portanto, esses mecanismos de incentivo à expansão dessa categoria, que se deu primeiramente de forma mais acentuada no bioma Pantanal, que depois se intensificou no Cerrado e na Mata Atlântica, têm relevância direta e explicam em parte porque a categoria detém o maior número de UCs no estado ao lado das APAs.

Pellin e Ranieri (2009) apresentam um contraponto a esse respeito em seus estudos sobre as motivações para o estabelecimento de RPPNs no estado de Mato Grosso do Sul, onde abordam as dificuldades enfrentadas para o reconhecimento dessas áreas e os incentivos para sua criação. Dentre as motivações pesquisadas entre os proprietários de RPPNs, a motivação primária mais frequente para a criação dessas áreas é a de "conservar espécies ou ecossistemas", seguidos de "satisfação pessoal" e "proteger os recursos hídricos" - com a motivação "obter isenção do imposto" aparecendo apenas em quarto lugar dentre as motivações mais frequentes para a criação dessas áreas.

No que diz respeito à localização das categorias por biomas no estado, é importante visualizar a distribuição geral desse período (até 2010) das UCs, onde já se pode evidenciar certas tendências no que se refere à criação de determinadas categorias e seu grupo de proteção (Proteção Integral e Uso Sustentável) no Cerrado, Pantanal e Mata Atlântica, como mostra a Figura 2.

\footnotetext{
${ }^{16}$ As RPPNs Portal do Pantanal Sul I, Portal do Pantanal Sul II, B'Longalé, Laudelino Barcellos estão fora do cálculo por não apresentarem o polígono no SISLA.
} 


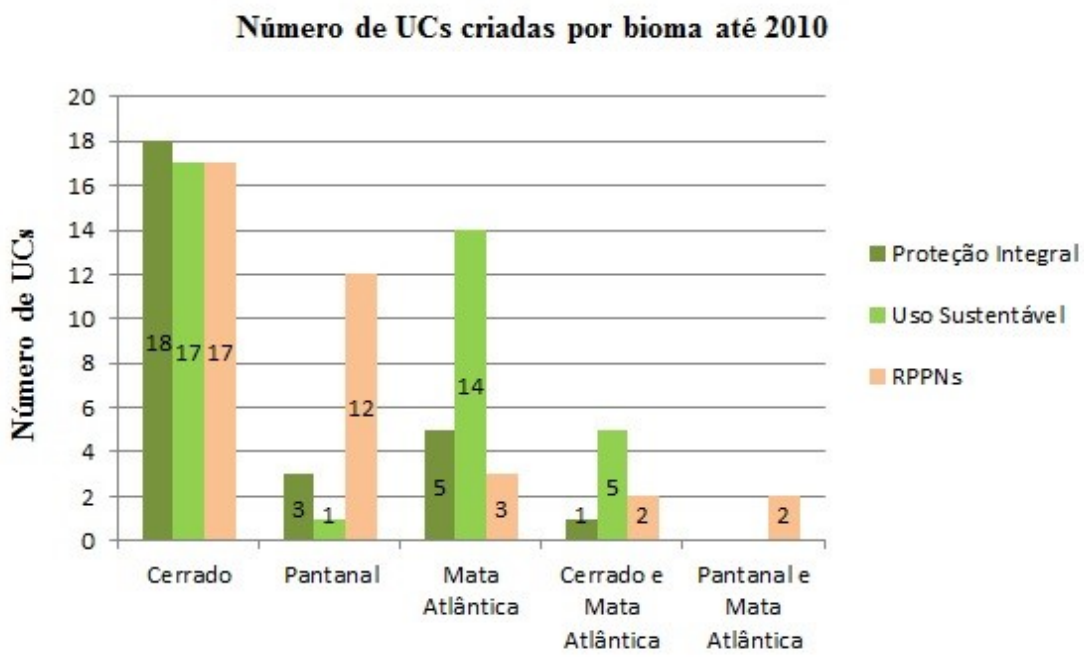

Figura 2 - Unidades de conservação criadas em Mato Grosso do Sul por bioma até o ano de 2010. Fonte: Elaborado com base nos dados de CEUC (2018).

No bioma Cerrado observa-se um equilíbrio entre os grupos de UCs no que diz respeito ao número. Todavia, as áreas ocupadas pelo grupo de US, que é representada em sua totalidade pela categoria APA, apresenta uma abrangência de 1.914.186,800 ha, enquanto as de PI somam 58.983,185 ha e RPPNs apresentam área em torno de 15.150,110 ha. Em estudos sobre a conversão da vegetação do Cerrado, Santos (2018) observou a mesma predominância de UCs de Uso Sustentável em número de unidades e extensão, especificamente da categoria APA, para o restante do bioma Cerrado nas demais unidades da federação, o que mostra não ser uma característica exclusiva do estado de Mato Grosso do Sul.

No caso das APAS, além das características de grande extensão de terra citadas inclusive na própria Lei do SNUC, uma especificidade quanto à sua localização no estado de Mato Grosso do Sul tem relação com o que está previsto no Decreto Estadual n ${ }^{\circ} 10.478 / 01$, onde em seu parágrafo $5^{\circ}$, Artigo $2^{\circ}$, menciona-se que “[...] para efeito de benefício ao município, o manancial de abastecimento público registrado deverá ser conservado sob o regime de área de proteção ambiental”. Portanto, a localização de grandes extensões de APAs ao longo do alto e médio curso do rio Sucuriú, ao Leste do estado, e próximas ao rio Paraná ao Sul/Sudeste do estado, tem como intenção, conforme indica o Decreto, o tratamento diferenciado de crédito aos municípios detentores dessas áreas e como resultado esperado o fornecimento de água potável para os municípios vizinhos.

Se comparado em número de UCs da categoria RPPN, o bioma Cerrado possuía até 2010 número maior em relação ao bioma Pantanal, que contabilizava 12 UCs dessa categoria. Porém, sua extensão territorial para essa categoria no bioma Pantanal era quase seis vezes maior com 87.440,323 ha. Um dos motivos para esse comportamento também é abordado por Pellin e Ranieri (2009), que, ao explanarem a respeito do Imposto Territorial Rural (ITR) como influência para motivar a criação de RPPNs no estado, indicam que este fator passa a ser mais atrativo e importante em RPPNs maiores, 
influenciadas por sua localização em áreas com baixo potencial para a produção agropecuária, como algumas regiões do Pantanal.

No caso do bioma Mata Atlântica, observa-se que as UCs de Uso Sustentável no estado, até 2010, eram em sua maioria APAs, com aproximadamente 1.760.143,452 ha, localizadas ao Sul do estado, próximas ao rio Paraná. Havia também um PARNA, um PE e três PNMs com um total de 102.911,543 ha, além de três RPPNs. Outras oito UCs estão localizadas em áreas de transição entre os biomas Cerrado e Mata Atlântica, sendo cinco APAS, um PARNA e duas RPPNs, além de duas RPPNs entre os biomas Pantanal e Mata Atlântica.

Em suma, observa-se que no período que compreende desde a primeira UC criada pelo estado em 1981 e passados os 10 primeiros anos após a criação da Lei do SNUC, Mato Grosso do Sul dispunha de 92 UCs (Tabela 2).

Tabela 2 - Unidades de Conservação criadas no estado até 2010.

\begin{tabular}{cccc}
\hline $\begin{array}{c}\text { Grupo de } \\
\text { Manejo }\end{array}$ & Número de UCs & $\begin{array}{c}\text { Área em } \\
\text { Hectares (ha) }\end{array}$ & Área no Estado (\%) \\
\hline Proteção Integral & 19 & $320.038,843$ & 0,89 \\
Uso Sustentável & 38 & $3.635 .299,581$ & 10,14 \\
RPPNs* & 35 & $119.294,716$ & 0,33 \\
Total & $\mathbf{9 2}$ & $\mathbf{4 . 0 7 4 . 6 3 3 , 1 4 0}$ & $\mathbf{1 1 , 3 3}$ \\
\hline
\end{tabular}

Fonte: Elaborada com base nos dados de CEUC (2018).

O avanço territorial detectado nas UCs de Proteção Integral Sul-mato-grossenses durante o período de 2001 a 2010 foi apenas de $0,12 \%$ de sua área. No caso das RPPNs, esse avanço representou 0,33\%, enquanto as UCs de Uso Sustentável obtiveram um avanço de 7,97\%.

Nos últimos nove anos (entre 2011 a 2019) houve uma retração significativa no avanço da criação de UCs, principalmente no que tange às UCs de Proteção Integral, com apenas mais 0,03\% de território destinado a essas unidades. Duas novas categorias do grupo de Proteção Integral foram incorporadas no estado, sendo uma Estação Ecológica (ESEC), com 3.038,722 ha, e dois Refúgios da Vida Silvestre (RVS), que somados possuem 3.007,040 ha. Além dessas, foram criados mais dois MONAs (2.781,883 ha) e duas REBIOs ${ }^{17}$ (876,601 ha). Quanto às UCs de Uso Sustentável, somaramse mais cinco APAs, alcançando 1.347.996,941 ha. A categoria RPPN foi responsável pelo maior número de UCs nesse período, sendo 18 unidades com uma área total de 15.752,861 ha.

Desse modo, até o presente momento, o estado de Mato Grosso do Sul (Figura 3) conta com 131 UCs, sendo 35 de Proteção Integral, 43 de Uso Sustentável e 53 RPPNs, somando-se um total de 15,20\% (Tabela 3) de sua área em todos os grupos de proteção.

\footnotetext{
${ }^{17}$ REBIO Marechal Cândido Mariano Rondon não está no cálculo por não possuir polígono de sua área cadastrado.
} 


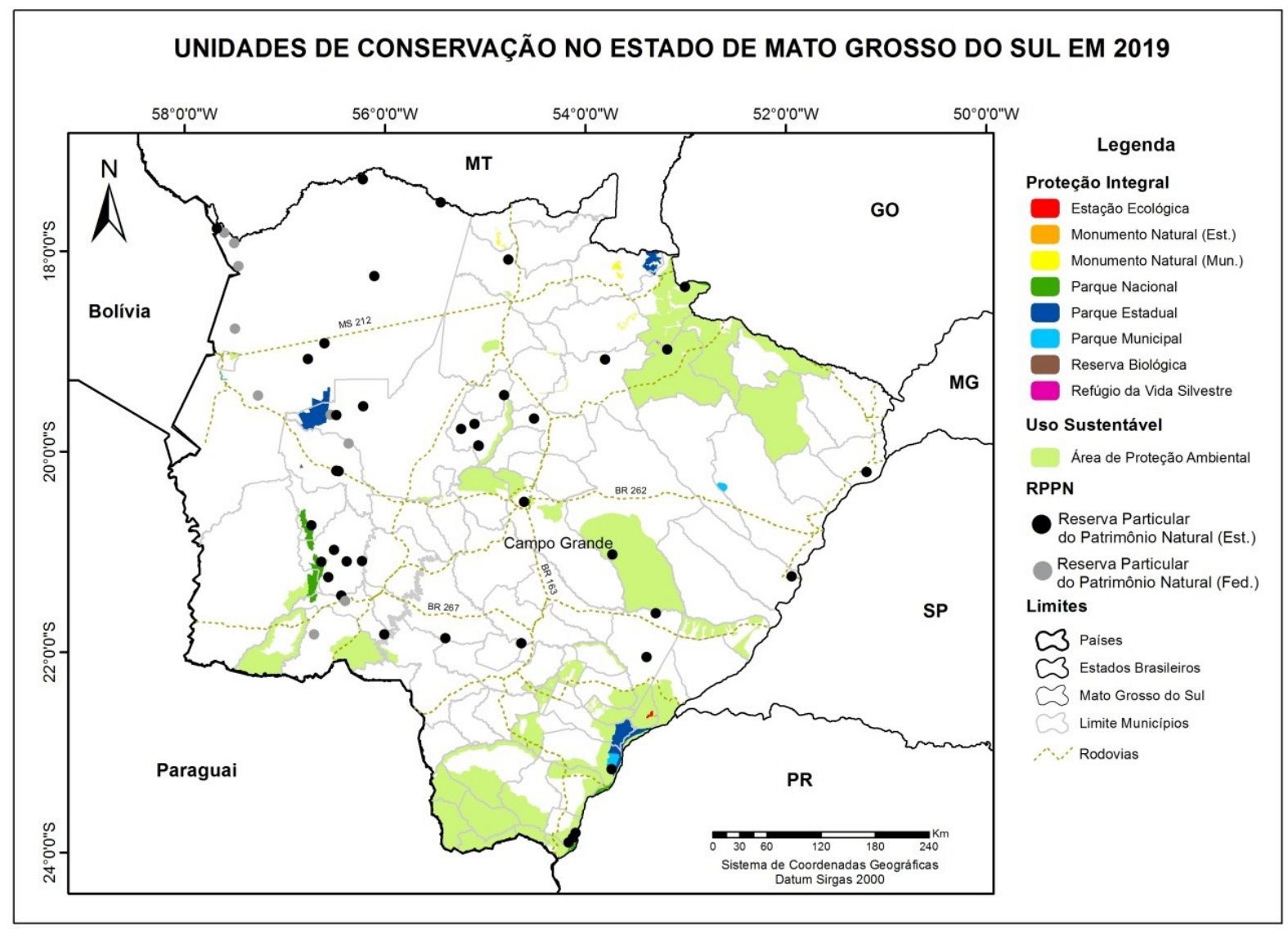

Figura 3 - Mapa de unidades de conservação no estado de Mato Grosso do Sul em 2019.

Fonte: Elaborado pelo autor (2020).

Tabela 3 - Unidades de Conservação em Mato Grosso do Sul por categorias e área de abrangência.

\begin{tabular}{cccc}
\hline Categorias & $\begin{array}{c}\text { Número de } \\
\text { UCs }\end{array}$ & $\begin{array}{c}\text { Área de abrangência no Estado } \\
(\text { ha })\end{array}$ & $\begin{array}{c}\text { Área de abrangência no Estado } \\
(\%)\end{array}$ \\
\hline Proteção Integral & $\mathbf{3 5}$ & $\mathbf{3 2 9 . 7 4 3 , 0 8 9}$ & $\mathbf{0 , 9 2 0 0}$ \\
PARNA & 4 & $94.326,268$ & 0,2630 \\
PE & 5 & $183.763,983$ & 0,5124 \\
PNM & 13 & $25.915,200$ & 0,0722 \\
MONA Est. & 2 & 294,422 & 0,0008 \\
MONA Mun. & 5 & $18.457,191$ & 0,0514 \\
ESEC & 1 & $3.038,722$ & 0,0084 \\
REBIO & 3 & 940,263 & 0,0026 \\
RVS & 2 & 3007,040 & 0,0083 \\
Uso Sustentável & $\mathbf{4 3}$ & $\mathbf{4 . 9 8 3 . 2 9 6 , 5 2 1}$ & $\mathbf{1 3 , 9 0 0 0}$ \\
APA & 43 & $4.983 .296,521$ & 13,9000 \\
Uso Sustentável & $\mathbf{5 3}$ & $\mathbf{1 3 5 . 5 3 9 , 2 8 5}$ & $\mathbf{0 , 3 8 0 0}$ \\
(Indireto) & & & 0,3800 \\
RPPNs & 53 & $135.539,285$ & $\mathbf{1 5 , 2 0 0 0}$ \\
Total* & $\mathbf{1 3 1}$ & $\mathbf{5 . 4 4 8 . 5 7 8 , 8 9 5}$ & $\mathbf{2 0 0}$ \\
\hline
\end{tabular}

* A Área de Especial Interesse Turístico Estrada Parque Pantanal não foi computada no cálculo por não fazer parte oficialmente do SNUC.

Fonte: CEUC (2018).

Levando em consideração a porcentagem total de abrangência de UCs no estado, que é atualmente de 15,20\%, nota-se um avanço significativo em relação ao observado até o ano 2000, que era de 3,14\%. Contudo, é válido destacar um movimento mais moroso quando se trata da criação de 
UCs do grupo de Proteção Integral, que avançou neste período 51.561,522 ha, o que corresponde a apenas $0,15 \%$ nas últimas duas décadas.

A extensão de áreas protegidas integralmente no estado em termos percentuais, sendo $0,92 \%$ de seu território, obtém menor representatividade se comparado com outras unidades da federação, como Mato Grosso, com 1,91\% de seu território (1.740.805 ha), e Goiás, com 1,45\% (493.987 ha), na região Centro-Oeste; e estados limítrofes da região Sudeste e Sul, como São Paulo com 4,13\% (1.025.861 ha), Minas Gerais com 2,25\% (1.334.838 ha) e o estado do Paraná com 2,32\% (461.976 ha) (CNUC, 2019).

No que concerne à abrangência do grupo de Proteção Integral, Torrecilha et al. (2017), em seus estudos sobre o registro de espécies ameaçadas de extinção em Mato Grosso do Sul com ênfase nas UCs, apontam a disparidade entre as áreas de Proteção Integral e de Uso Sustentável no estado, assinalando a necessidade de uma revisão das estratégias empregadas na rede de UCs do estado, com o intuito de proporcionar maior equilíbrio na questão do manejo e da biodiversidade.

Ainda segundo Torrecilha et al. (2017), obtiveram-se, em seu estudo, 292 registros de 38 espécies de aves e 628 registros de 20 espécies de mamíferos ameaçadas, onde dentre estes, 34 espécies de aves apresentaram pelo menos um registro no interior UCs de um total de 119 registros. No caso dos mamíferos, 19 espécies apresentaram pelo menos um registro no interior de UCs de um total de 279 registros. É interessante observar que, dentre as categorias de UCs analisadas, os Parques Nacionais, os Parques Estaduais e as RPPNs apresentaram o maior número de abrigo para as espécies ameaçadas, como por exemplo o Parque Nacional das Emas, o Parque Estadual Pantanal do Rio Negro e RPPN Rio Negro.

As grandes extensões destinadas a UCs de Uso Sustentável, que representam nesse caso $91,46 \%$ de todas as unidades, em sua maioria APAs, não necessariamente implicam em áreas protegidas mal manejadas ou com pouca biodiversidade. Porém, demandam uma atenção especial, à medida que estão suscetíveis a altos graus de interferência antrópica.

Dessa forma, se destacado o exemplo da APA das bacias do rio Aporé e do rio Sucuriú, anteriormente citado, em Chapadão do Sul, que faz parte de um mosaico com outras seis APAs municipais no Leste do estado, é possível apontar algumas das interferências antrópicas citadas. Segundo dados da área sobre o uso e cobertura da terra em 2018, adquiridos através do projeto Mapbiomas, ${ }^{18}$ dos 298.702,918 ha destinados a UC, 43,18\% são ocupados por pastagem; 29,93\% por cultura anual e perene; e 6,46\% por cultura semiperene, somando 79,57\% do território da unidade. As classes relacionadas à formação florestal, savânica e campestre e à floresta plantada somaram ao todo $19,91 \%$.

18 Dados coletados a partir Projeto MapBiomas, Coleção 4.0 e calculados em ambiente SIG. 
Nesse contexto, além de fatores como a diversidade de espécies e genética, a diversidade de fisionomias da vegetação e de paisagens, encontradas nas UCs, relacionam-se também com as funções ecossistêmicas e podem garantir um grau maior ou menor de biodiversidade em função de seu uso e cobertura da terra e de suas modificações (LEWINSOHN e PRADO, 2005; GRACIOLLI et al., 2017).

Quanto à distribuição dessas áreas por biomas, das 131 UCs contabilizadas em 2019, percebe-se de certa forma uma tendência referente à sua espacialização, onde 71 estão localizadas no bioma Cerrado, 33 na Mata Atlântica, 17 no Pantanal, oito em Cerrado e Mata Atlântica e duas em Pantanal e Mata Atlântica. A figura 4 mostra os grupos de proteção existentes em cada bioma e a Tabela 4 sua área de abrangência.

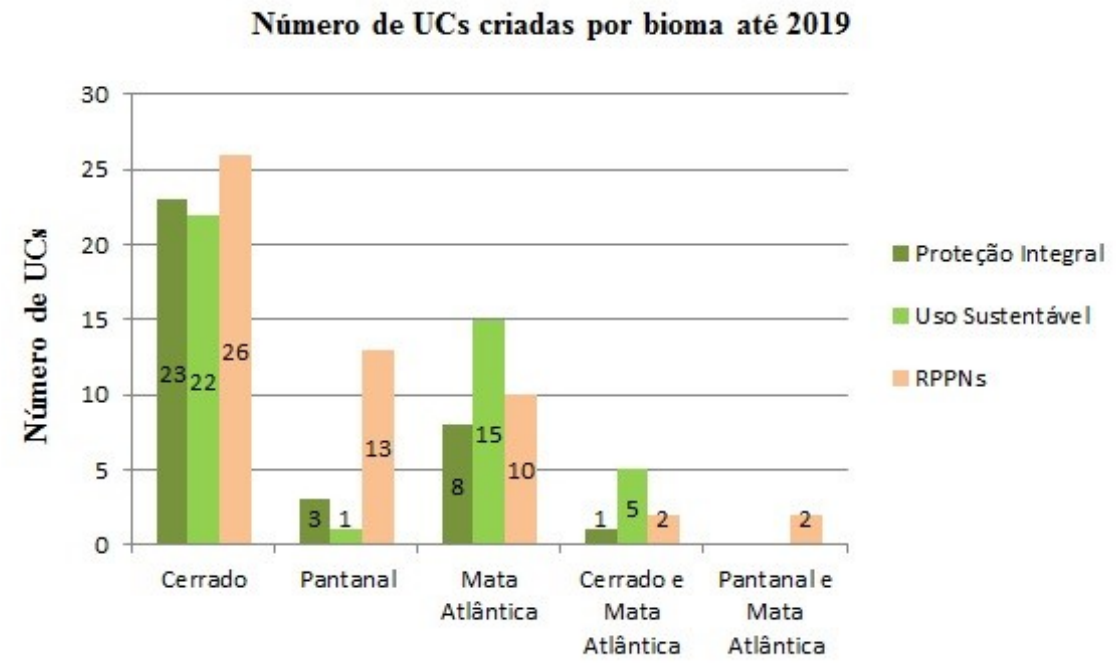

Figura 4 - Número de unidades de conservação existentes por bioma em MS até 2019. Fonte: Elaborado com base nos dados de CEUC (2018).

Tabela 4 - Unidades de conservação e sua abrangência territorial nos biomas Cerrado, Mata Atlântica e Pantanal em Mato Grosso do Sul.

\begin{tabular}{|c|c|c|c|c|c|}
\hline $\begin{array}{c}\text { Grupos/ } \\
\text { Categorias }\end{array}$ & Cerrado & $\begin{array}{c}\text { Mata } \\
\text { Atlântica }\end{array}$ & Pantanal & $\begin{array}{c}\text { Cerrado e } \\
\text { Mata } \\
\text { Atlântica }\end{array}$ & $\begin{array}{c}\text { Pantanal e } \\
\text { Mata Atlântica }\end{array}$ \\
\hline $\begin{array}{l}\text { Proteção } \\
\text { Integral }\end{array}$ & 23 & 8 & 3 & 1 & - \\
\hline PARNA & 1 & 1 & 1 & 1 & - \\
\hline $\mathrm{PE}$ & 3 & 1 & 1 & - & - \\
\hline PNM & $9 *$ & 3 & 1 & - & - \\
\hline MONA Est. & 2 & - & - & - & - \\
\hline MONA Mun. & 5 & - & - & - & - \\
\hline ESEC & - & 1 & - & - & - \\
\hline REBIO & 1 & $2 *$ & - & - & - \\
\hline RVS & 2 & - & - & - & - \\
\hline Área (ha) & $64.863,507$ & $106.826,866$ & $80.463,554$ & $77.589,162$ & - \\
\hline Uso & 22 & 15 & 1 & 5 & - \\
\hline \multicolumn{6}{|l|}{ Sustentável } \\
\hline APAs & $22 *$ & 15 & 1 & 5 & - \\
\hline Área (ha) & $3.002 .581,290$ & $1.775 .141,075$ & $6.190,888$ & $199.383,270$ & - \\
\hline
\end{tabular}




$\begin{array}{lccccc}\begin{array}{l}\text { Uso } \\ \text { Sustentável } \\ \text { (Indireto) }\end{array} & \mathbf{2 6} & \mathbf{1 0} & \mathbf{1 3} & \mathbf{2} & \mathbf{2} \\ \text { RPPNs } & 26^{*} & 10^{*} & 13^{*} & 2^{*} & 2 \\ \text { Total de UCs } & \mathbf{7 1} & \mathbf{3 3} & \mathbf{1 7} & \mathbf{8} & \mathbf{2} \\ \text { Área (ha) } & 27.358,757 & 3.444,908 & 88.579,487 & - & 16.156,131 \\ \quad \begin{array}{c}\text { Área Total } \\ \quad \text { (ha) }\end{array} & 3.094 .803,554 & 1.885 .412,849 & 175.233,929 & 276.972,432 & 16.156,131\end{array}$

* As UCs: APA da bacia do Rio Paranaíba, Parque Natural Municipal Piray, Reserva Biológica Marechal Cândido Mariano Rondon, RPPNs Lageado, B'Longalé, Laudelino Barcellos e Nova Querência não apresentam polígono da área.

Fonte: Elaborada com base nos dados de CEUC (2018).

Algumas características importantes podem ser apontadas quanto à distribuição das UCs por bioma em Mato Grosso do Sul como:

a) Obtendo maior número de UCs de Proteção Integral, o bioma Cerrado possui menos hectares em relação ao bioma Mata Atlântica e Pantanal, que são impulsionados pela extensão de UCs da categoria Parque, como o Parque Estadual das Várzeas do Rio Ivinhema (74.297,144), localizado no bioma Mata Atlântica, e o Parque Estadual do Pantanal do Rio Negro (78.535,755 ha), no Pantanal. Apesar do bioma Cerrado possuir um maior número de Parques na esfera Federal, Estadual e Municipal, individualmente estes têm menor extensão territorial.

b) O bioma Cerrado possui a maior quantidade de UCs em número e extensão territorial voltado ao uso direto dos recursos naturais, por meio da categoria APA, representando 55,11\% de todas as áreas destinadas a UCs no estado. Em termos gerais, o bioma Cerrado reserva até o momento 97,02\% das áreas com UCs para o Uso Sustentável, 2,10\% para a Proteção Integral e 0,88\% para RPPNs.

c) As UCs localizadas apenas no bioma Mata Atlântica possuem a maior extensão territorial voltada para Proteção Integral, correspondendo a 32,40\% do total deste grupo.

d) Embora o bioma Cerrado possua 26 UCs da categoria RPPN, o bioma Pantanal apresenta maior extensão territorial com 88.579,487 ha, distribuídos em 19 unidades.

e) As UCs localizadas entre Cerrado e Mata Atlântica, em sua maioria, são de Uso Sustentável, sendo cinco APAs, um PARNA e duas RPPNs.

Essas características são de certa forma influenciadas pelo enfoque nas estratégias regionais de conservação e por aspectos administrativos do Sistema Estadual de Unidades de Conservação. Em se tratando da questão administrativa de sistemas dessa natureza, tanto em âmbito nacional como estadual, Brito (2000) aponta alguns fatores que podem influenciar direta e indiretamente no sucesso desse processo, como, por exemplo, vontade política, situação original da área, clareza dos objetivos, adequação da categoria, localização, envolvimento da população local, políticas setoriais discordantes e a capacidade gerencial do poder público. 
No Brasil, segundo o CNUC (2019), das 2376 UCs cadastradas, 1706 (71,80\%) não possuem conselho gestor e 1946 (81,90\%) não possuem plano de manejo. Dentre os 79 municípios existentes em MS, em 74 existe pelo menos uma UC, o que mostra a abrangência do Sistema Estadual de Unidades de Conservação e a importância de um planejamento estruturado para o suporte dessas áreas. Sabendo da importância do acesso sobre os dados dessas áreas, a Tabela 4 mostra a disponibilidade de acesso de algumas informações cadastrais das UCs nas esferas Federal e Estadual, discriminadas por categoria.

Tabela 4 - Disponibilidade de dados sobre as unidades de conservação por categoria.

\begin{tabular}{|c|c|c|c|c|c|}
\hline Categorias & $N^{\circ}$ de UCs & $\begin{array}{c}\text { UCs cadastradas } \\
\text { no CEUC } \\
\end{array}$ & $\begin{array}{c}\text { UCs cadastradas } \\
\text { no CNUC }\end{array}$ & $\begin{array}{c}\text { UCs com } \\
\text { Plano de Manejo }\end{array}$ & $\begin{array}{c}\text { Polígono } \\
\text { cadastrado no SISLA }\end{array}$ \\
\hline PI & 35 & $\mathbf{3 0}$ & 25 & 14 & $\mathbf{3 3}$ \\
\hline PARNA & 4 & 3 & 4 & 3 & 4 \\
\hline PE & 5 & 5 & 5 & 5 & 5 \\
\hline PNM & 13 & 12 & 6 & 5 & 12 \\
\hline MONA Est. & 2 & 2 & 2 & - & 2 \\
\hline MONA Mun. & 5 & 4 & 2 & 1 & 5 \\
\hline ESEC & 1 & 1 & 1 & - & 1 \\
\hline REBIO & 3 & 1 & 3 & - & 2 \\
\hline RVS & 2 & 2 & 2 & - & 2 \\
\hline $\mathbf{U S}$ & 43 & 41 & 6 & 2 & 42 \\
\hline APA & 43 & 41 & 6 & 2 & 42 \\
\hline \multicolumn{6}{|l|}{ US (Indireto) } \\
\hline & 53 & 53 & 28 & 9 & 49 \\
\hline RPPN* & 53 & 53 & 28 & 9 & 49 \\
\hline Total & 131 & 124 & 59 & 25 & 124 \\
\hline
\end{tabular}

Fonte: Elaborada com base nos dados de CEUC (2015) e CNUC (2019).

Percebe-se uma desconexão entre as informações que são disponibilizadas nas plataformas Estadual e Federal quanto ao número de UCs cadastradas e também o baixo número de unidades que possuem plano de manejo - em torno de $19 \%$ do total. A Tabela 4 mostra que sete UCs não apresentam os arquivos de sua delimitação no SISLA, por motivos de pendências cadastrais, o que impossibilita o cálculo total da extensão dessas áreas.

Sabe-se que a ausência de determinados dados, vitais para a constituição do planejamento, prejudicam a confecção de produtos e informações voltadas para a tomada de decisão. Brito (2000), ao discorrer sobre a estrutura organizacional e a capacidade administrativa das instituições, afirma que não há estrutura administrativa ideal, mas que é possível melhorar sua eficiência com base em diretrizes que permitam “[...] fomentar a fluidez de informações e a capacidade de análise” (BRITO, 2000, p.49).

Observando a necessidade de dados sobre as UCs, é necessário que essas áreas possuam uma gestão e um plano de manejo adequados, que atendam os pressupostos da categoria para a consolidação de suas funções e não apenas sirvam de instrumento para o ordenamento territorial da região (ESTEVES e SOUZA, 2014). 


\section{CONSIDERAÇÕES FINAIS}

Mesmo analisando que o movimento de criação e implantação das UCs mais intenso seja considerado recente, nota-se o avanço das Áreas Protegidas por Unidades de Conservação tanto em número de unidades, quanto em extensão territorial no estado de Mato Grosso do Sul, principalmente após a criação da Lei do SNUC.

A princípio, o pioneirismo na criação de RPPNs nos anos 1990 e dos Parques Estaduais entre 1998 a 2000 foi a principal iniciativa para a conservação dos recursos naturais mediante seu uso de forma indireta, mantendo-se o avanço da categoria Parque na esfera municipal, principalmente entre os anos de 2001 a 2010.

Paralelamente, o aumento expressivo das UCs de uso sustentável representadas pelas APAs, principalmente na esfera municipal, delineou uma forma característica da expansão dessas unidades no estado, privilegiando as áreas de uso direto dos recursos naturais com 91,46\% de todo o sistema. Esse cenário evidencia um claro desequilíbrio em número e extensão de território dos grupos de proteção, sendo necessária a observação da efetiva administração, da proteção da biodiversidade e de questões como a homogeneização e a fragmentação da paisagem, principalmente em grandes áreas como das APAs localizadas ao Leste e ao Sul do Estado.

Em relação à disposição das UCs por bioma, é interessante observar que o Cerrado, apesar de apresentar maior extensão territorial no Estado e também maior extensão em UCs, ainda apresenta menores áreas protegidas do grupo de Proteção Integral em relação aos biomas Mata Atlântica e Pantanal. Enquanto no estado do MS, o bioma Pantanal apresenta grande representatividade com a presença das RPPNs, o bioma Mata Atlântica têm nos Parques maiores extensões de áreas protegidas pelo uso indireto dos recursos naturais.

Quanto à questão da disponibilização dos dados e a desconexão em alguns casos de determinadas informações, sugere-se que seja discutida a possibilidade de implantação de um sistema virtual integrado, que permita a acessibilidade tanto de forma interna para os órgãos competentes e seus funcionários, como para usuários externos, de acesso a informações atualizadas, como planos de manejo, delimitação das unidades, registros fotográficos, ICMS ecológico, potencialidades e também possíveis pendências administrativas, além de outras informações que sejam essenciais para as tomadas de decisão.

Entende-se que os avanços conquistados nos últimos anos com o maior número de UCs em todo estado e suas políticas de incentivo são de suma importância para a conservação da biodiversidade no estado do Mato Grosso do Sul. Servem, ainda, de apoio para a constante conscientização da população para as questões ambientais. Entretanto, é necessário que a busca pela representatividade por diferentes categorias de manejo seja o alvo principal das próximas políticas 
ambientais no estado, entendendo que a garantia da biodiversidade também passa pela pluralidade nas formas de uso destes ambientes em busca de um equilíbrio natural.

\section{AGRADECIMENTOS}

O presente trabalho foi realizado com apoio da Coordenação de Aperfeiçoamento de Pessoal de Nível Superior - Brasil (CAPES) - Código de Financiamento 001. Os autores agradecem ainda ao apoio institucional do Campus de Três Lagoas da Universidade Federal de Mato Grosso do Sul e da Financiadora de Estudos e Projetos (FINEP).

\section{REFERÊNCIAS}

ARAUJO, M. A. R. Unidades de Conservação no Brasil: da república à gestão de classe mundial. Belo Horizonte: SEGRAG, 2007. 272p.

BARRETO, C.; DRUMMOND, J. A. L. Strategic Planning in Brazilian Protected Areas: Uses and Adjustments. Journal of Environmental Management, v. 200, p. 79-87, 2017.

BRASIL. Decreto n 23.793, de 23 de janeiro de 1934. Aprova o Código Florestal Brasileiro.

BRASIL. Decreto $n^{0}$ 49.874, de 11 de janeiro de 1961. Cria o "Parque Nacional das Emas", no Estado de Goiás, abrangendo parte menor, do Estado de Mato Grosso.

BRASIL. Lei n. ${ }^{\circ} 4.771$ de 15 de setembro de 1965. Institui o novo Código Florestal (Revogado).

BRASIL. Lei $\mathbf{n}^{\circ}$ 5.197, de 3 de janeiro de 1967. Dispõe sobre a proteção à fauna e dá outras providências.

BRASIL. Lei no 6.513, de 20 de dezembro de 1977. Dispõe sobre a criação de Áreas Especiais e de Locais de Interesse Turístico; sobre o Inventário com finalidades turísticas dos bens de valor cultural e natural; acrescenta inciso ao art. $2^{\circ}$ da Lei $\mathrm{n}^{\circ} 4.132$, de 10 de setembro de 1962; altera a redação e acrescenta dispositivo à Lei $\mathrm{n}^{\circ} 4.717$, de 29 de junho de 1965; e dá outras providências.

BRASIL. Lei No 6.902, de 27 de abril de 1981. Dispõe sobre a criação de Estações Ecológicas, Áreas de Proteção Ambiental e dá outras providências.

BRASIL. Lei $\mathbf{n}^{\circ}$ 9.985, de 18 de julho de 2000. Regulamenta o artigo $225, \S 1^{\circ}$, incisos I, II, III e VII da Constituição Federal, institui o Sistema Nacional de Unidades de Conservação da Natureza e dá outras providências. Disponível em: https://www.planalto.gov.br/ccivil_03/leis/19985.htm. Acesso em: 02 set. 2019.

BRASIL. Decreto $\mathbf{n}^{\mathbf{0}}$ 89.336, de 31 de janeiro de 1984. Dispõe sobre as Reservas Econômicas e Áreas de Relevante Interesse Ecológico, e dá outras providências.

BRASIL. Decreto n 86.392, de 24 de setembro de 1981. Cria, no Estado de Mato Grosso, o Parque Nacional do Pantanal Mato-Grossense.

BRASIL. Decreto s/no de 21 de setembro de 2000. Cria o Parque Nacional da Serra da Bodoquena. 
BRASIL, Ministério do Meio Ambiente. $4^{0}$ Relatório Nacional para a Convenção sobre Diversidade Biológica. Série Áreas Protegidas do Brasil n. 7. Brasília: Secretaria de Biodiversidade e Florestas, Ministério do Meio Ambiente, 2010. 28p.

BRASIL, Ministério do Meio Ambiente. Sistema Nacional de Unidades de Conservação da Natureza - SNUC lei $n^{\circ}$ 9.985, de 18 de julho de 2000; decreto $n^{\circ} 4.340$, de 22 de agosto de 2002. 5.ed. aum. Brasília: MMA/SBF, 2004. 56p.

BRITO, M. C. W. Unidades de conservação: intenções e resultados. 1. ed. São Paulo: Annablume; Fapesp, 2000. 230p.

CDB. Programme of Work on Protected Areas, 2010. Disponível em: www.cbd.int/protected/pow/ learnmore/intro/. Acesso em: 24 set. 2019.

DIEGUES, A. C. O mito moderno da natureza Intocada. 1. ed. São Paulo: NUPAUB-USP, 2008. $189 \mathrm{p}$.

DORST, J. Antes que a natureza morra. 1. ed. São Paulo: Blucher, 1973. 416p.

DOUROJEANNI, J. M; PÁDUA, M. T. J. Arcas à deriva: unidades de conservação no Brasil. 1. ed. Rio de Janeiro: Technical Books, 2013. 350p.

DRUMMOND, J. A.; FRANCO, J. L. A.; OLIVEIRA, D. Uma análise sobre a história e a situação das unidades de conservação no Brasil. In: GANEM, R. (org.). Conservação da biodiversidade: legislação e políticas públicas. Série Memória e Análise de Leis, n. 2. Brasília: Edições Câmara, 2011. $437 \mathrm{p}$.

DUDLEY, N. Guidelines for Applying Protected Area Management Categories. Gland: IUCN. 2008. 86p.

ESTEVES, A. O.; SOUZA, M. P. Avaliação Ambiental Estratégica e as Áreas de Proteção Ambiental. Revista Engenharia Sanitária e Ambiental, v. 19, p. 77-86, 2014.

FRANCO, J. L. A.; DRUMMOND, J. A. Proteção à natureza e identidade nacional no Brasil, anos 1920-1940. 1. ed. Rio de Janeiro: Ed. Fiocruz, 2009, 272p.

GRACIOLLI, G.; ROQUE, F. O.; FARINACCIO, M. A.; SOUZA, P. R.; PINTO, J. O. P. Montando o quebra-cabeça da biodiversidade de Mato Grosso do Sul. Iheringia, Série Zoologia, 107, p. 1-7, 2017.

GUC. Gerência de Unidades de Conservação. Dados ICMS Ecológico/2017. Campo Grande, 2017.

HOCKINGS, M.; STOLTON, S.; LEVERINGTON, F.; DUDLEY, N.; COURRAU, J. Evaluating Effectiveness: A framework for assessing management effectiveness of protected areas. IUCN, Cambridge: IUCN, 2006. 214p.

IMASUL - INSTITUTO DE MEIO AMBIENTE DE MATO GROSSO DO SUL. Plano de Manejo do Parque Estadual do Prosa. Campo Grande, dezembro de 2011. Disponível em: www.servicos.ms.gov.br/imasuldownloads/PlanosdeManejo/planomanejoPEP.pdf. Acesso em: 15 out. 2019. 
IMASUL - INSTITUTO DE MEIO AMBIENTE DE MATO GROSSO DO SUL. Plano de Manejo do Parque Estadual das Várzeas do Rio Ivinhema. Campo Grande, 2008. Disponível em: www.servicos.ms.gov.br/imasuldownloads/PlanosdeManejo/planomanejoPEVRI.pdf. Acesso em: 10 out. 2019.

JENKINS, C. N.; JOPPA, L. Expansion of the Global Terrestrial Protected Area System. Biological Conservation, v. 142, n. 10, p. 2166-2174, 2009.

KLINK, C. A.; MACHADO, R. B. A conservação do Cerrado Brasileiro. Revista Megadiversidade, v. 1, n. 1, p. 147-155, 2005.

LEWINSOHN, T. M.; PRADO, P. I. How many species are there in Brazil? Conservation Biology, v. 19, n. 3, p. 619-624, 2005.

MATO GROSSO DO SUL. Decreto n⿳ 9.278, de 17 de dezembro de 1998. Cria o Parque Estadual das Várzeas do Rio Ivinhema, e dá outras providências.

MATO GROSSO DO SUL. Decreto $\mathbf{n}^{\mathbf{0}} \mathbf{1 0 . 7 8 3}$, de 21 de maio de 2002. Cria o Parque Estadual do Prosa e dá outras providências.

MATO GROSSO DO SUL. Decreto $\mathbf{n}^{\circ} \mathbf{1 2 . 5 2 8}$, de 27 de março de 2008. Institui o Sistema de Reserva Legal (SISREL) no Estado do Mato Grosso do Sul.

MATO GROSSO DO SUL. Lei $\mathbf{n}^{\mathbf{0}}$ 2.259, de 9 de julho de 2001. Dispõe sobre o rateio do índice de $5 \%$ (cinco por cento) previsto no artigo $1^{\circ}$, III, " $\mathrm{f}$ ", da Lei Complementar $\mathrm{n}^{\circ}$ 057, de 4 de janeiro de 1991, com redação dada pela Lei Complementar $n^{0}$ 077, de 07 de dezembro de 1994, e dá outras providências.

MATO GROSSO DO SUL. Lei Complementar $\mathbf{n}^{0}$ 077, de 07 de dezembro de 1994. Altera a redação de dispositivo da Lei Complementar nº 57, de 4 de janeiro de 1991, e dá outras providências.

MATO GROSSO DO SUL. Lei Estadual no 4.219, de 11 de julho de 2012. Dispõe sobre o ICMS Ecológico na forma do art. $1^{\circ}$, inciso III, alínea " $\mathrm{f}$ ", da Lei Complementar $\mathrm{n}^{\circ} 57$, de 4 de janeiro de 1991, na redação dada pela Lei Complementar $n^{\circ} 159$, de 26 de dezembro de 2011, e dá outras providências.

MATO GROSSO DO SUL. ZEE-MS - Zoneamento Ecológico-Econômico do Estado: Segunda Aproximação. Elementos para construção da sustentabilidade do território Sul-mato-grossense. 1. ed. Campo Grande: SEMAGRO, 2014. 199p.

MEDEIROS, R. Evolução das tipologias e categorias de áreas protegidas no Brasil. Ambiente \& Sociedade, v. 9, n. 1, p. 41-64, jan./jun. 2006.

MERCADANTE, M. Uma década de debate e negociação: a história da elaboração da Lei do SNUC. In: BENJAMIN, A. H. (org.) Direito Ambiental das Áreas Protegidas. Rio de Janeiro: Ed. Forense Universitária, 2001, p. 190-231.

MILANO, M. S. Parques e reservas: uma análise da política brasileira de unidades de conservação. Revista Floresta, v. 15, n. 2, p. 4-9, 1984.

MOREIRA, A. D. A Gestão do ICMS ecológico no Mato Grosso do Sul. 2004. Dissertação (Mestrado em Meio Ambiente e Desenvolvimento Regional) - Universidade Para o Desenvolvimento do Estado e da Região do Pantanal, Campo Grande, 2004. 
NASCIMENTO, A. C. Plano de manejo do Parque do Prosa. Campo Grande, 2011. Disponível em: www.imasul.ms.gov.br/gestao-de-unidades-de-conservacao/unidades-de conservacao-estaduais/parque-estadual-do-prosa-pep/. Acesso em: 20 ago. 2019.

PÁDUA, M. T. J. Do sistema nacional de unidades de conservação. In: MEDEIROS, R; ARAÚJO, F. F. S. (Orgs). Dez anos do Sistema Nacional de Unidades de Conservação da Natureza: lições do passado, realizações presentes e perspectivas para o futuro. Brasília: MMA, 2011. 220 p. 220p.

PELLIN, A.; RANIERI, V. E. L. Motivações para o estabelecimento de RPPNs e análise dos incentivos para sua criação e gestão no Mato Grosso do Sul. Natureza \& Conservação, v. 7, n. 2, p. 72-81, out. 2009.

PUREZA, F. A. Histórico de criação das categorias de unidades de conservação no Brasil. 2014. 247 f. Dissertação (Mestrado em Conservação da Biodiversidade e Desenvolvimento Sustentável) Instituto de Pesquisas Ecológicas, Escola Superior de Conservação Ambiental e Sustentabilidade, Nazaré Paulista, 2014.

RODRIGUES, M. T. Conservação dos répteis brasileiros: os desafios para um país megadiverso. Revista Megadiversidade, v. 1, n. 1, p. 87-94, 2005.

RYLANDS, A. B.; BRANDON, K. Unidades de conservação brasileiras. Megadiversidade, v. 1, n. 1, p. 27-35, 2005.

SANTOS, S. A. As Unidades de Conservação no Cerrado Frente ao Processo de Conversão. 2018. 105 f. Dissertação (Mestrado em Geografia) - Instituto de Estudos Socioambientais, Universidade Federal de Goiás, Goiânia, 2018.

SANTOS, F. C.; KRAWIEC, V. A. M. A Situação Ambiental e a Administração das Unidades de Conservação em Campo Grande-MS, na Visão de seus Gestores. Floresta e Ambiente, v. 18, n. 3, p. 334-342, 2011.

SISLA. Sistema Interativo de Suporte ao Licenciamento Ambiental. Disponível em: http://sisla.imasul.ms.gov.br/sisla/pagina_inicial2.php. Acesso em: 28 nov. 2019.

TABARElli, M.; PINTO, L. P.; SILVA, J. M. C.; HOROTA, M. M.; BEDÊ, L. C. Desafios e oportunidades para a conservação da biodiversidade na Mata Atlântica Brasileira. Revista Megadiversidade, v. 1, n. 1, p. 132-138, 2005.

TORRECILHA, S.; GONÇALVES, R. M.; LAPS, R. R.; TOMAS, W. M.; MARANHÃO, H. L.; ROQUE, F. O. Registros de espécies de mamíferos e aves ameaçadas em Mato Grosso do Sul com ênfase no Sistema Estadual de Unidades de Conservação. Iheringia, Série Zoologia, n. 107, p. 1-7, 2017. 